\title{
Dynamic Fracture-Initiation Toughness Determination of Al 7075-T651 Aluminum Alloy
}

\begin{abstract}
We present values of the static and dynamic fracture-initiation toughness at different loading rates of the aluminum alloy Al 7075-T651 obtained on three-point bend specimens with different thicknesses and initial crack lengths. In static conditions, the critical stress intensity factor was measured according to well known procedures. The methodology of dynamic fracture initiation toughness is not yet standardized, and the dynamic tests were done with a modified Hopkinson pressure bar coupled to high-speed cameras to measure the crack mouth opening displacement (CMOD) of the specimens. The critical stress intensity value was obtained from the CMOD at the time that crack starts to grow. This instant was detected by means of crack gauges at the crack tip.
\end{abstract}

KEYWORDS: dynamic bending test, dynamic initiation toughness, modified Hopkinson pressure bar, high-speed photography

\section{Introduction}

The integrity of mechanical and structural components subjected to dynamic loading requires the knowledge of the fracture behavior of the material at high strain rates. Considering mode I fracture, several dynamic fracture parameters may be defined in relation to the crack propagation regime. The dynamic fracture-initiation toughness $\left(K_{I d}\right)$ represents the value of the stress intensity factor (SIF) at which a crack starts to propagate.

Other dynamic fracture parameters are the dynamic fracture propagation toughness $\left(K_{I D}\right)$ and the crack arrest toughness $\left(K_{I A}\right)$. These three material fracture parameters are used in design, but the first is of special significance because it determines the effective propagation of a crack within a structural element subjected to impulsive load.

In contrast to the methodology adopted for the determination of static fracture toughness $\left(K_{I c}\right)$, that of dynamic fracture initiation toughness $\left(K_{I d}\right)$ is not yet standardized. The instrumented Charpy test has been widely used to evaluate the dynamic fracture properties of materials, but different authors [1-5] have proposed special arrangements of the split Hopkinson pressure bar for dynamic bending tests that allow higher strain rates than those reached by instrumented Charpy impact tests.

The aluminum alloy Al-7075-T651 is much used in aeronautic structures. Its fracture behavior in static conditions is well known, but less is known of the influence of dynamic loads on the fracture properties of the alloy.

Here we present an experimental procedure to obtain fracture properties at different loading rates and has been applied on aluminum alloy Al-7075-T651 specimens with different initial crack length and specimen thickness. The method to obtain the critical SIF in static conditions is based on ASTM standard procedure [6].

\footnotetext{
${ }^{1}$ Assistant Professor, Department of Continuum Mechanics and Structural Analysis, University Carlos III of Madrid, Avda. de la Universidad, 30, 28911 Leganés, Madrid, Spain.

${ }^{2}$ Professor, Department of Continuum Mechanics and Structural Analysis, University Carlos III of Madrid, Avda. de la Universidad, 30, 28911 Leganés, Madrid, Spain.
}

The dynamic tests were performed in a modified Hopkinson Pressure Bar (MHPB) and the critical stress intensity factor was obtained as the value of the stress intensity factor at the instant that the crack began to grow (the so called time to fracture). The SIF was calculated from the crack mouth opening displacement (CMOD), measured with four high-speed cameras coupled to the modified Hopkinson Pressure Bar, and the time to fracture was detected by crack gauges at the crack tip.

\section{Material and Test Specimens}

The chemical composition and the tensile properties in static conditions of the Al-7075-T651 are presented in Tables 1 and 2.

The specimens were designed according to the ASTM Standard ASTM E 399 [6]. Their dimensions were: width $W=20 \mathrm{~mm}$, span $S=80 \mathrm{~mm}$, and total length $L=100 \mathrm{~mm}$. The specimens were notched in $T-L$ direction and fatigue pre-cracked to give crack lengths of about $30 \%, 50 \%$, and $70 \%$ of the specimen width $(a / W=0.3,0.5,0.7)$. A particular notch shape was mechanized for the short crack case $(a / W=0.3)$. Figure 1 shows a scheme of the specimen geometry. The notch width $(h)$ and the notch angle $(\theta)$ were $h=2 \mathrm{~mm}$ and $\theta=45^{\circ}$.

Specimens of different thicknesses were used $(B=5 \mathrm{~mm}$ and $B$ $=10 \mathrm{~mm}$ ) for the same $L$ and $W$, to test the effect of this dimension on the fracture properties.

\section{Static Test Procedure}

Static three-point bending tests were performed in an INSTRON 8516 testing machine. The applied load was measured using a load cell of $100 \mathrm{kN}$ capacity and the load-point displacement with a linear variable differential transformer. A detail of the static experimental setup is shown in Fig. 2.

TABLE 1-Chemical composition of Al-7075-T651 alloy (wt. \%).

\begin{tabular}{ccccccccc}
\hline $\mathrm{Si}$ & $\mathrm{Fe}$ & $\mathrm{Cu}$ & $\mathrm{Mn}$ & $\mathrm{Mg}$ & $\mathrm{Cr}$ & $\mathrm{Zn}$ & $\mathrm{Ti}$ & $\mathrm{Al}$ \\
\hline 0.100 & 0.160 & 1.620 & 0.050 & 2.620 & 0.200 & 5.870 & 0.036 & Balance \\
\hline
\end{tabular}




\begin{tabular}{lccccc}
\hline $\begin{array}{l}\text { Young's modulus } \\
E, \mathrm{GPa}\end{array}$ & $\begin{array}{c}\text { Yield Strength } \\
\sigma_{0.2}, \mathrm{MPa}\end{array}$ & $\begin{array}{c}\text { Ultimate Strength } \\
\sigma_{U T S}, \mathrm{MPa}\end{array}$ & $\begin{array}{c}\text { Poisson's } \\
\text { Ratio } \nu\end{array}$ & $\begin{array}{c}\text { Elongation } \\
\text { at break } \\
\delta, \%\end{array}$ & $\begin{array}{c}\text { Mass Density } \\
\rho, \mathrm{kg} / \mathrm{m}^{3}\end{array}$ \\
\hline 72 & 505 & 570 & 0.33 & 11 & 2810 \\
\hline
\end{tabular}

In each test, from the load versus load-point displacement curve the value of $P_{Q}$ (Fig. 3) was determined according to ASTM E 399 standard procedure [6].

The initial crack length of the specimens tested $(\bar{a})$ was determined as the average of three measurements at equidistant points through the thickness (Fig. 4) using a profile projector (NIKON, model V-20A).

Finally, the critical stress intensity factor was computed as [6]:

$$
K_{Q}=\frac{P_{Q} S}{B W^{3 / 2}} f\left(\frac{\bar{a}}{W}\right)
$$

with:

$$
f\left(\frac{\bar{a}}{W}\right)=\frac{3\left(\frac{\bar{a}}{W}\right)^{1 / 2}\left[1.99-\frac{\bar{a}}{W}\left(1-\frac{\bar{a}}{W}\right)\left(2.15-3.93 \frac{\bar{a}}{W}+2.7\left(\frac{\bar{a}}{W}\right)^{2}\right)\right]}{2\left(1+2 \frac{\bar{a}}{W}\right)\left(1-\frac{\bar{a}}{W}\right)^{3 / 2}}
$$

In most cases, the requirements of the ASTM E 399 were not achieved due to the initial crack-length values used. Only the specimens with $a / W=0.5$ and $B=10 \mathrm{~mm}$ meet the $\mathrm{E} 399$ requirements. For this reason, the $K_{Q}$ notation is adopted instead of $K_{c}$ or $K_{I c}$.

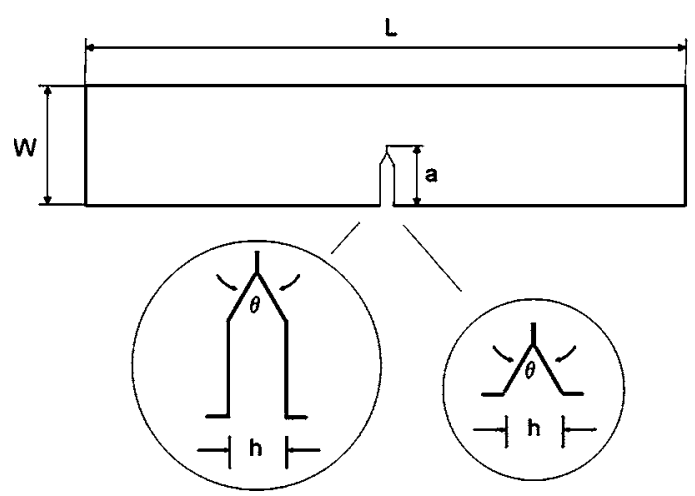

FIG. 1-Geometry of the specimens tested.

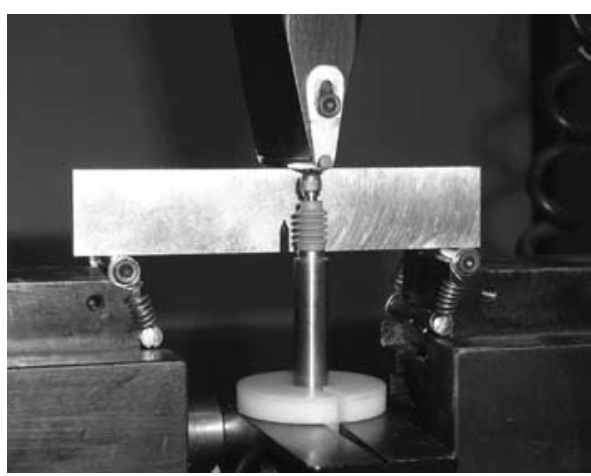

FIG. 2-Static bending test detail.

\section{Dynamic Test Procedure}

\section{Experimental Setup}

Figure 5 shows a scheme of the experimental setup used in the dynamic tests. It consists of a striker bar (projectile), an input bar, a

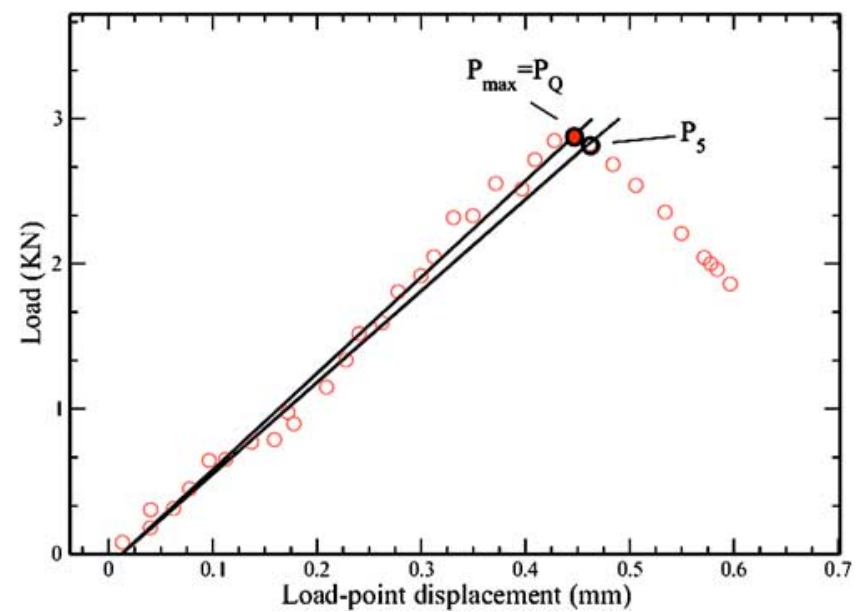

FIG. 3-Load versus load-point displacement curve in a static test.

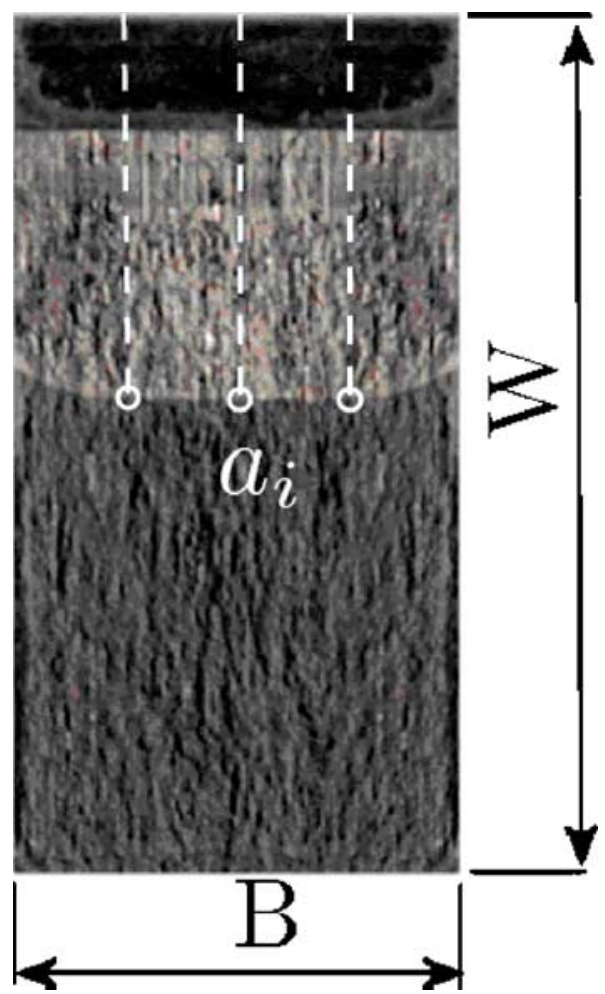

FIG. 4-Crack length measurement. 


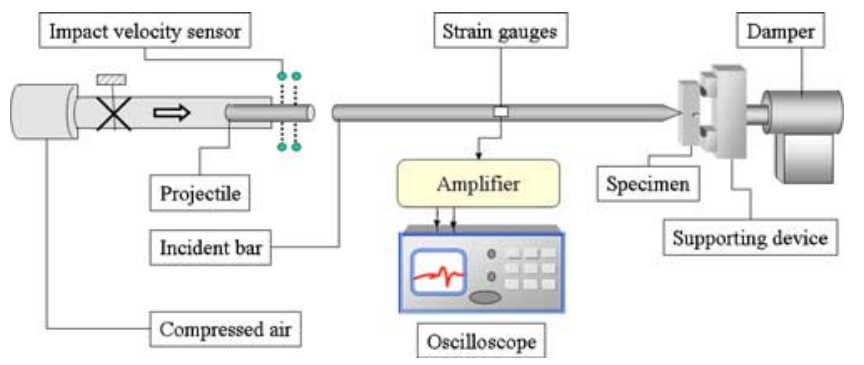

FIG. 5-Experimental setup for dynamic tests.

specimen supporting device, and a data acquisition system. The projectile and the input bar are cylindrical of $22 \mathrm{~mm}$ in diameter, and the lengths are $330 \mathrm{~mm}$ and $1 \mathrm{~m}$, respectively. The striking end of the input bar is geometrically similar to the nose of the Charpy hammer.

The cracked specimen was carefully aligned between the input bar and the supporting device to ensure that the crack surface and the contact line of the input bar were in the same plane. The specimen was loaded to fracture by a concentrated transverse force applied at its mid-span by the impact of the projectile on the input bar at the desired velocity $\left(V_{0}\right)$.

Dynamic stress intensity factor-The evaluation of the critical stress intensity factor in dynamic conditions involves first the calculation of the temporal evolution of the dynamic stress intensity factor $\left(K_{I}(t)\right)$ and secondly, the determination of the time to fracture.

The critical stress intensity factor $\left(K_{Q}\right)$ is the value of the stress intensity factor at the instant of propagation of the crack (time to fracture, $t_{f}$ ):

$$
K_{Q}=K_{I}\left(t_{f}\right)
$$

To calculate the temporal evolution of the $\operatorname{SIF}\left(K_{I}(t)\right)$ in dynamic bending tests, different numerical approaches have been proposed $[2,8,9]$, as well as several experimental procedures such as optical [10-12] and photoelastic [13] techniques, requiring complex equipment. Other authors, using the Euler-Bernoulli [14] or Timoshenko [15] beam theories, derived simple formulas for the dynamic SIF of three-point bending specimens. To use these formulas, the applied load on the specimen and its natural frequencies must be known. Nishioka et al. [16] computed the dynamic SIF from the CMOD, assuming that the relationship deduced for the static condition applies to the dynamic one. Bacon et al. [3] rearranged the formula of Nishioka et al. [16] to obtain the dynamic SIF from the load point displacement. Recently, Popelar et al. [17] proposed a dynamic test method in which the fracture toughness is estimated from the crack opening displacement (COD), evaluated from the CMOD (which is measured by means of a gauge) using a simple quasi-dynamic model.

We calculated the temporal evolution of the dynamic stress intensity factor $\left(K_{I}(t)\right)$ from the CMOD values $\left(w_{m}\right)$, assuming that the relationship that exists in static conditions can be applied in the dynamic one [16]. In this case, $K_{I}(t)$ can be expressed as:

$$
K_{I}(t)=\frac{E w_{m}(t)}{4 \alpha \sqrt{W}} \frac{\kappa_{\beta}(\alpha)}{v_{\beta}(\alpha)}
$$

where $\alpha$ and $\beta$ are defined as:

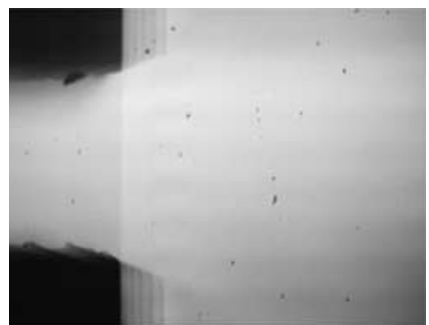

(a)

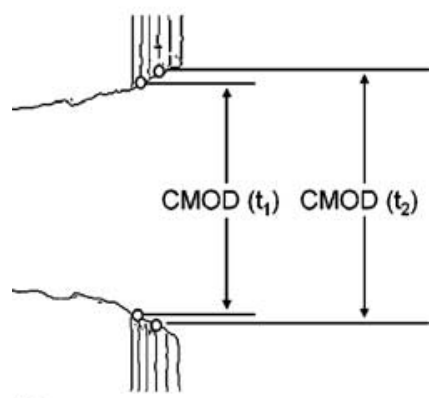

(b)

FIG. 6-Photographs taken by a CCD camera. (a) Original frame. (b) Postprocessed frame.

$$
\alpha=\frac{\bar{a}}{W}, \quad \beta=\frac{S}{W}
$$

In equation $4, \kappa_{\beta}(\alpha)$ and $v_{\beta}(\alpha)$ are non-dimensional functions depending on $\alpha$ and $\beta$ values. Their expressions are given in [18]. For $\beta=4$, these expressions are:

$$
\kappa_{\beta}(\alpha)=\frac{\sqrt{\alpha}}{(1-\alpha)^{3 / 2}(1+3 \alpha)}\left(1.9+0.41 \alpha+0.51 \alpha^{2}-0.17 \alpha^{3}\right)
$$

$$
v_{\beta}(\alpha)=0.76-2.28 \alpha+3.87 \alpha^{2}-2.04 \alpha^{3}+\frac{0.66}{(1-\alpha)^{2}}
$$

The initial crack lengths were measured by the procedure for the static tests.

\section{CMOD Measurement}

To calculate the dynamic stress intensity factor according to Eq 4, the temporal evolution of CMOD $\left(w_{m}(t)\right)$ was obtained with four high-speed cameras coupled to the experimental device. This equipment consists of four coupled CCD cameras (PCO, mod. FLASHCAM) that can take images of a common objective (a $50 \times$ magnification lens). The specimen was illuminated from the side opposite to the cameras, so the images visualized are the shadow of the specimen (Fig. 6(a)). The first signal recorded by a strain gage placed on the input bar near the impacted end of the projectile served to synchronize with the cameras.

The cameras, designated a, b, c, and d, take several pictures with a selected delay between each one (Table 3). The exposure time of the photographs is $1 \mu \mathrm{s}$. The cameras start to record after this initial delay, following the impact of the projectile on the input bar. The initial delay and the delay between photographs are different for each camera. 
TABLE 3-Configuration of the CCD cameras.

\begin{tabular}{lcccc}
\hline Camera & $\mathrm{a}$ & $\mathrm{b}$ & $\mathrm{c}$ & $\mathrm{d}$ \\
\hline Number of images & 6 & 6 & 6 & 6 \\
Exposure time, $\mu \mathrm{s}$ & 1 & 1 & 1 & 1 \\
Delay, $\mu \mathrm{s}$ & 3 & 5 & 8 & 14 \\
Initial delay, $\mu \mathrm{s}$ & 180 & 185 & 190 & 195 \\
\hline
\end{tabular}

The photographs taken by a camera at different times are superimposed in a single frame, as shown in Fig. 6(a).

The photographs were treated with an image-processing software that distinguished the contours of the different timed images. The CMOD on the specimen surface was measured directly from these treated images (Fig. 6(b)).

\section{Determination of the Time to Fracture}

The instant at which the crack on the specimen surface initiates its propagation, (time to fracture $t_{f}$ ), was obtained with crack propagation gauges at the crack tip of the specimen (Fig. 7(a)).

These gauges, made of electric wires normal to the direction of the crack propagation, break as the crack grows, varying the resistivity of the gauge. The signal recorded by the gauges is shown in Fig. 7(b). The time to fracture was determined as the instant at which the medium value of the voltage gap is reached (see Fig. $7(b))$.

From the SIF time-histories obtained from CMOD (Eq 4), and the time to fracture $t_{f}$ the critical stress intensity factor in dynamic conditions $\left(K_{Q}\right)$ can be evaluated from Eq 3 .

Rubio et al. [5] reported that the determination of SIF time-

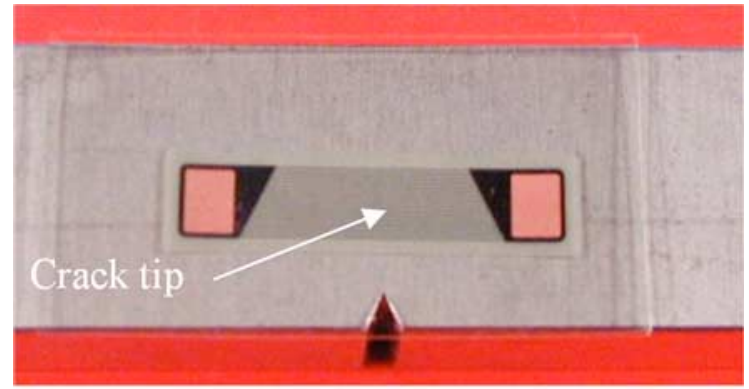

(a)

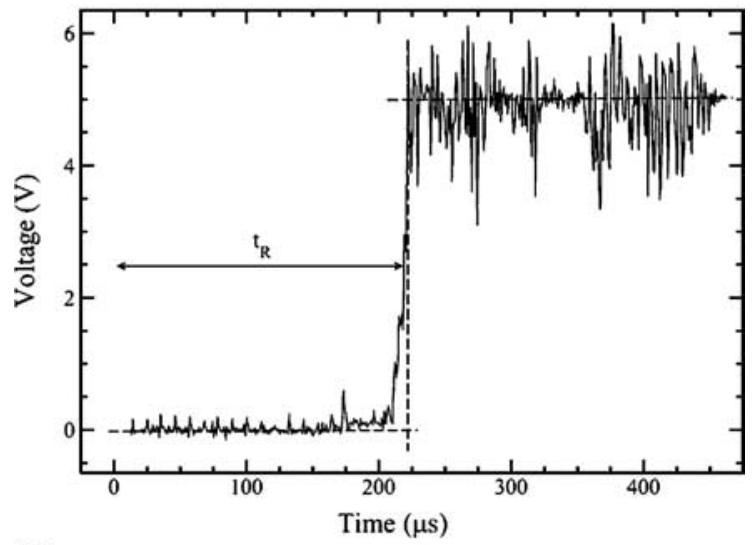

(b)

FIG. 7-Determination of time to fracture. (a) Crack propagation gauge location. (b) Signal from crack propagation gauge.
TABLE 4-Critical stress intensity factor in static conditions.

\begin{tabular}{lcc}
\hline$a / W$ & $B, \mathrm{~mm}$ & $K_{O}, \mathrm{MPa} \mathrm{m}^{0.5}$ \\
\hline $0.31 \pm 0.02$ & 5 & $31.2 \pm 0.8$ \\
$0.30 \pm 0.01$ & 10 & $24.6 \pm 0.1$ \\
$0.50 \pm 0.02$ & 5 & $26.0 \pm 0.7$ \\
$0.51 \pm 0.01$ & 10 & $24.2 \pm 0.2$ \\
$0.71 \pm 0.02$ & 5 & $24.0 \pm 0.9$ \\
$0.70 \pm 0.01$ & 10 & $23.3 \pm 0.5$ \\
\hline
\end{tabular}

histories and the time to fracture obtained with crack gauges, provide a reliable method of measuring dynamic fracture-initiation toughness.

\section{Experimental Results}

Table 4 shows the mean values and standard deviations of the static critical stress intensity factor $\left(K_{Q}\right)$ of three specimens tested in each condition (initial crack length and specimen thickness). As has been previously stated, only the specimens with $a / W$ about 0.5 and $B=10 \mathrm{~mm}$ meet the E 399 requirements. The $K_{Q}$ obtained in these cases $\left(K_{Q}=24.2 \pm 0.2 \mathrm{MPa} \mathrm{m}^{0.5}\right)$ agree with other results published for the fracture toughness of this material $\left(K_{I C}=25 \mathrm{MPa} \mathrm{m}^{0.5}\right.$ for $T$ $L$ orientation) [7].
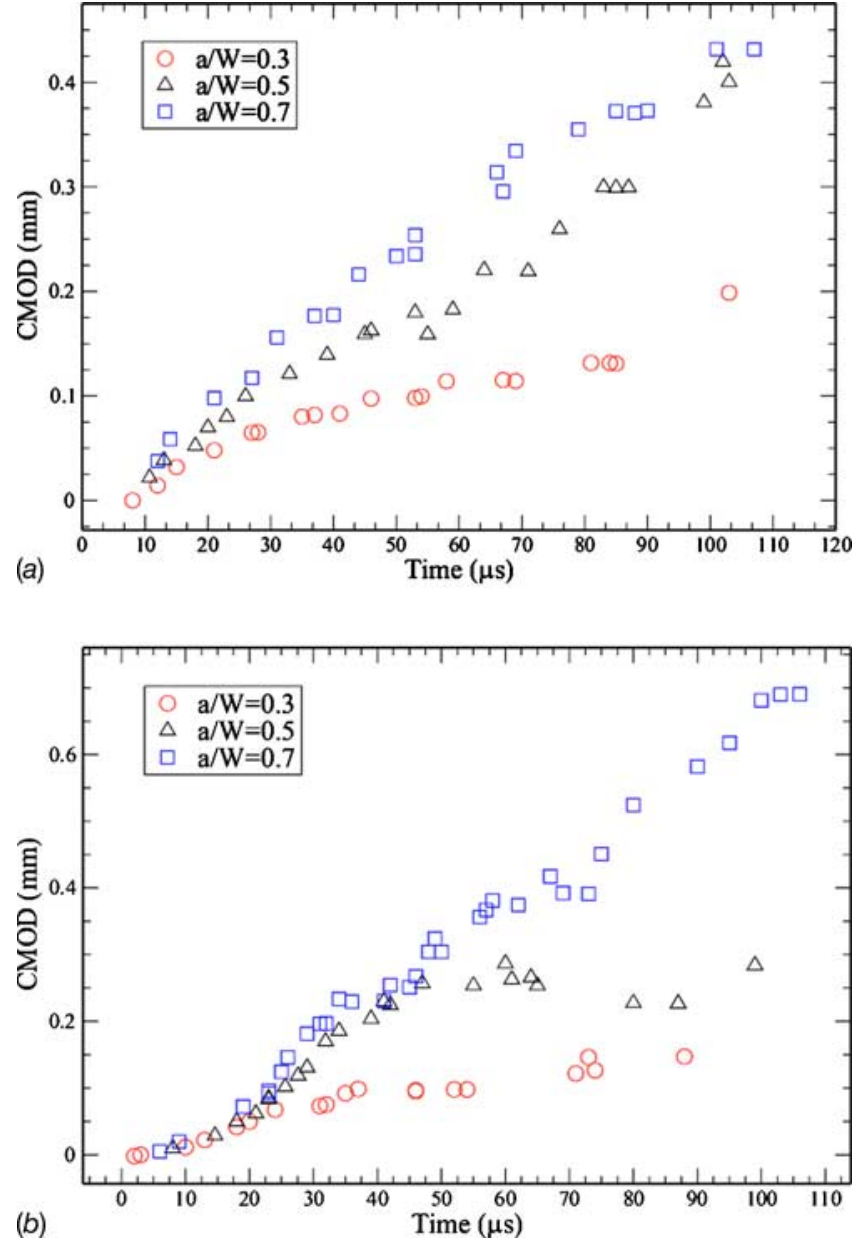

FIG. 8-Temporal evolution of CMOD $\left(V_{0}=5 \mathrm{~m} / \mathrm{s}\right)$. (a) $B=5 \mathrm{~mm}$. (b) $B$ $=10 \mathrm{~mm}$. 

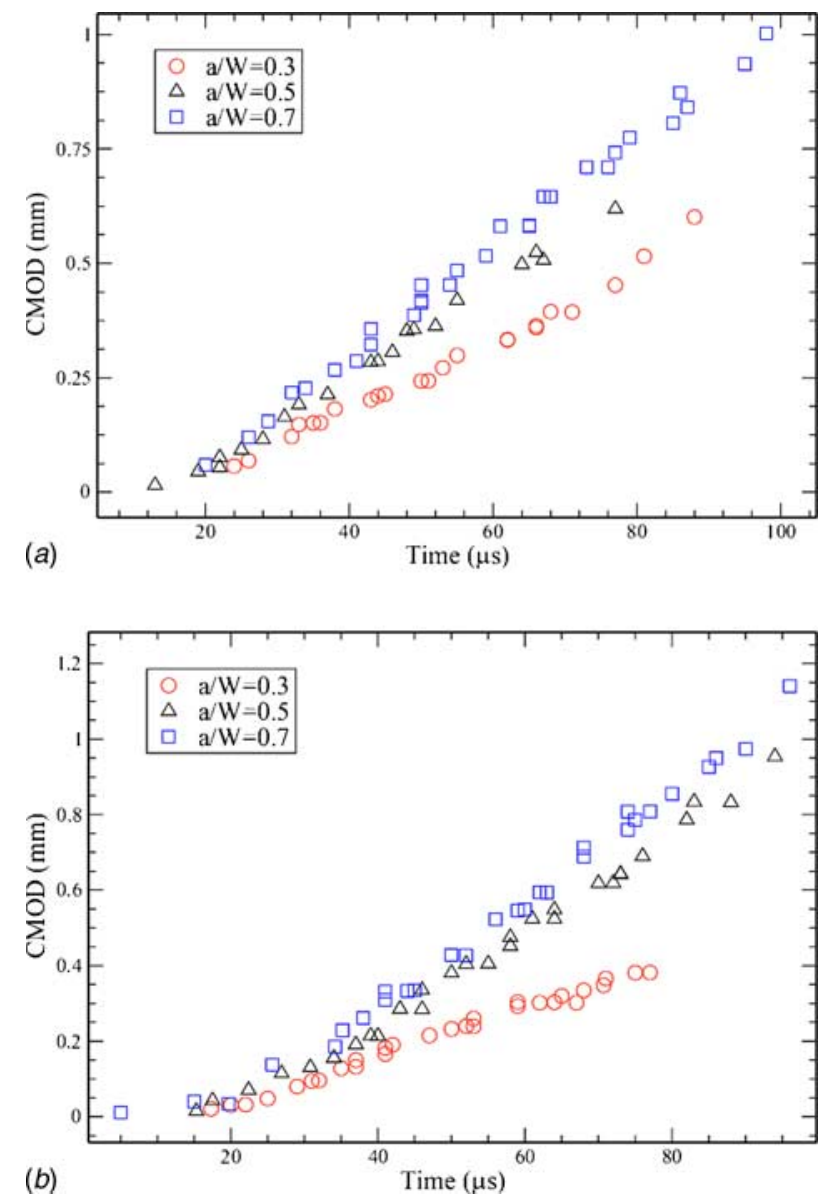

FIG. 9-Temporal evolution of CMOD $\left(V_{0}=10 \mathrm{~m} / \mathrm{s}\right)$. (a) $B=5 \mathrm{~mm}$. (b) $B$ $=10 \mathrm{~mm}$.

Figures 8 and 9 give the CMOD time-histories measured in the dynamic bending tests, with CCD cameras of specimens of different initial crack lengths, different thicknesses, and at two impact velocities: $V_{0}=5 \mathrm{~m} / \mathrm{s}$ (Fig. 8) and $V_{0}=10 \mathrm{~m} / \mathrm{s}$ (Fig. 9).

The CMOD time-history shown in these figures demonstrates that the CMOD measured is greater as the crack length is longer, due to greater specimen compliance. This difference is less at higher impact velocity.

The results corresponding to the time to fracture $\left(t_{f}\right)$, the CMOD value at this instant, as well as the dynamic critical stress intensity factor $\left(K_{Q}\right)$ are given in Tables $5\left(V_{0}=5 \mathrm{~m} / \mathrm{s}\right)$ and $6\left(V_{0}=10 \mathrm{~m} / \mathrm{s}\right)$. These correspond to the mean values and standard deviations of the results of three specimens tested in each condition.

These results of the dynamic tests present a wider scatter (standard deviation values) than in the static case, due to the practical

TABLE 5-Results of dynamic tests. $V_{0}=5 \mathrm{~m} / \mathrm{s}$.

\begin{tabular}{lcccc}
\hline$a / W$ & $B, \mathrm{~mm}$ & $t_{f}, \mu \mathrm{s}$ & $\begin{array}{c}\mathrm{CMOD} \text { at } t_{f}, \\
a \mathrm{~m}\end{array}$ & $K_{Q}, \mathrm{MPa} \mathrm{m}^{0.5}$ \\
\hline $0.31 \pm 0.01$ & 5 & $44 \pm 6$ & $85 \pm 6$ & $23.8 \pm 3.9$ \\
$0.30 \pm 0.01$ & 10 & $42 \pm 8$ & $80 \pm 4$ & $22.6 \pm 3.2$ \\
$0.52 \pm 0.01$ & 5 & $59 \pm 8$ & $139 \pm 6$ & $23.6 \pm 4.1$ \\
$0.53 \pm 0.02$ & 10 & $32 \pm 6$ & $132 \pm 3$ & $22.2 \pm 2.9$ \\
$0.70 \pm 0.02$ & 5 & $42 \pm 6$ & $216 \pm 6$ & $22.3 \pm 3.8$ \\
$0.71 \pm 0.02$ & 10 & $40 \pm 7$ & $205 \pm 7$ & $21.1 \pm 4.1$ \\
\hline
\end{tabular}

TABLE 6-Results of dynamic tests. $V_{0}=10 \mathrm{~m} / \mathrm{s}$.

\begin{tabular}{lcccc}
\hline & & \multicolumn{3}{c}{$\mathrm{CMOD}$ at $t_{f}}$, \\
$a / W$ & $B, \mathrm{~mm}$ & $t_{f}, \mu \mathrm{s}$ & $\mu \mathrm{m}$ & $K_{O}, \mathrm{MPa} \mathrm{m}^{0.5}$ \\
\hline $0.31 \pm 0.01$ & 5 & $31 \pm 6$ & $84 \pm 4$ & $23.7 \pm 3.1$ \\
$0.30 \pm 0.01$ & 10 & $34 \pm 6$ & $79 \pm 5$ & $22.5 \pm 3.1$ \\
$0.51 \pm 0.01$ & 5 & $38 \pm 5$ & $138 \pm 6$ & $23.4 \pm 4.2$ \\
$0.50 \pm 0.01$ & 10 & $32 \pm 7$ & $129 \pm 5$ & $22.0 \pm 3.1$ \\
$0.71 \pm 0.02$ & 5 & $35 \pm 4$ & $215 \pm 3$ & $22.3 \pm 3.8$ \\
$0.70 \pm 0.02$ & 10 & $38 \pm 9$ & $201 \pm 6$ & $20.7 \pm 4.1$ \\
\hline
\end{tabular}

difficulty of defining the instant that the crack initiates its propagation.

Using the presented technique, the critical stress intensity factor has been measured at different impact velocities on three point bend specimens with several values of initial crack length and thickness. These results and those obtained in static conditions are presented in Fig. 10.

The proposed method is a suitable procedure to obtain the dynamic fracture properties of materials. However, for the material tested, the small differences observed in the results do not permit extract clear conclusions about the effect of the specimen thickness or impact velocity on the fracture properties. To show most clearly this fact, as an example, the error bands for the $K_{Q}$ values on the specimens with $a / W=0.5$ in different test conditions are plotted in Fig. 11. As can be seen, all of the dynamic results fall in a wide scatter band and no conclusions about rate or thickness effects are possible.

\section{Summary and Conclusions}

We present an experimental technique to determine the critical stress intensity factor on specimens with different thickness and the initial crack length, at different impact velocities.

Static and dynamic three-point bending tests were performed on aluminum alloy Al-7075-T651 specimens with different thicknesses $(5$ and $10 \mathrm{~mm})$ and different initial crack lengths $(a / W$ $=0.3,0.5,0.7)$.

The static tests follow the ASTM standard procedure [6] and in dynamic conditions, the SIF was measured directly from the CMOD, using high-speed cameras coupled to the MHPB device.

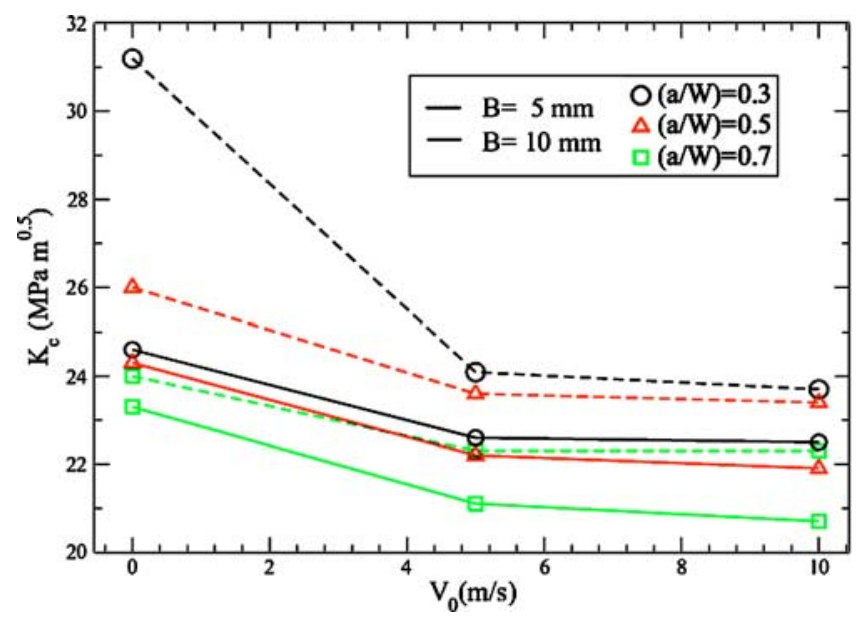

FIG. 10-Mean $K_{Q}$ values in different test conditions. 


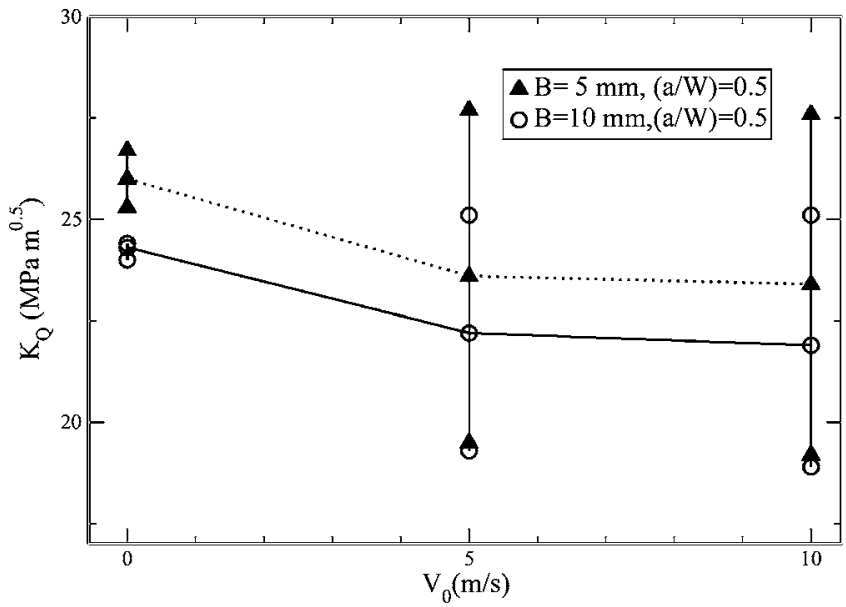

FIG. $11-$ Error bands for the $K_{Q}$ values on the specimens with $a / W=0.5$ in different test conditions.

The time to fracture was measured from crack gauges at the crack tip.

The experimental technique presented allows one to obtain the dynamic fracture properties of materials using three-point bend specimens with different thicknesses and initial crack lengths impacted at different velocities. For the material tested, no clear conclusions can be obtained about the effect of the specimen thickness or impact velocity effect on the fracture properties.

\section{References}

[1] Ruiz, C. and Mines, R., "The Hopkinson Pressure Bar: An Alternative to the Instrumented Pendulum for Charpy Test," Int. J. Fract., Vol. 29, 1985, pp. 101-109.

[2] Yokoyama, T., "Determination of Dynamic Fracture-Initiation Toughness Using a Novel Impact Bend Test Procedure," J. Pressure Vessel Technol., Vol. 115, 1993, pp. 389-397.

[3] Bacon, C., Färm, J., and Lataillade, J. L., "Dynamic Fracture Toughness Determined from Load-Point Displacement," Exp. Mech., Vol. 34, 1994, pp. 217-223.

[4] Rubio, L., "Determinación de parámetros de fractura dinámica a alta velocidad de deformación," Ph.D. thesis, Carlos III University of Madrid, 1999.

[5] Rubio, L., Fernandez-Saez, J., and Navarro, C., "Determination of Dynamic Fracture-Initiation Toughness Using Three-
Point Bending Tests in a Modified Hopkinson Pressure Bar," Exp. Mech., Vol. 43, 2003, pp. 379-386.

[6] ASTM Standard E 399-90, "Standard Test Method for PlainStrain Fracture Toughness of Metallic Materials," Annual Book of ASTM Standards, ASTM International, West Conshohocken, PA, 1994.

[7] "Properties and Selection: Nonferrous Alloys and SpecialPurpose Materials," Metals Handbook Vol. 2, 10th ed., ASM International, Metals Park, OH, 1990.

[8] Nishioka, T., Perl, M., and Atluri, S. N., "An Analysis of Dynamic Fracture in an Impact Test Specimen,” J. Pressure Vessel Technol., Vol. 105, 1983, pp. 124-131.

[9] Crouch, B. A., "Finite Element Modeling of the Three-Point Bend Impact Test," Comput. Struct., Vol. 48, 1993, pp. 167173.

[10] Beinert, J. and Kalthoff, J. F., "Experimental Determination of Dynamic Stress Intensity Factors by Shadow Patterns," Mechanics of Fracture, Vol. 7, 1981, pp. 281-330.

[11] Ravi-Chandar, K. and Knauss, W., "An Experimental Investigation Into Dynamic Fracture: I. Crack Initiation and Arrest," Int. J. Fract., Vol. 25, 1984, pp. 247-262.

[12] Benitez, F. and Andrade, L., "In-Plane Impact Loading of Composites: Optical Evaluation and Crack Severity Assessment for Graphite-Epoxy," J. Phys. IV, Vol. 7, 1997, pp. 169176.

[13] Dally, J. and Barker, D., "Dynamic Measurements of Initiation Toughness at High Loading Rates," Exp. Mech., Vol. 28, 1988, pp. 298-303.

[14] Kishimoto, K., Aoki, S., and Sakata, M., "Simple Formula for Dynamic Stress Intensity Factor of Pre-cracked Charpy Specimen," Eng. Fract. Mech., Vol. 13, 1980, pp. 501-508.

[15] Kishimoto, K., Kuroda, K., Aoki, S., and Sakata, M., "Simple Formulae for Dynamic Fracture Mechanics Parameters of Elastic and Viscoelastic Three Point Bend Specimens Based on Timoshenko's Beam Theory," Proc. 6th Int. Conf. on Fracture, New Delhi, India, S. Valluri et al., Eds., Vol. 5, 1984, pp. 3177-3184, Pergamon, Oxford.

[16] Nishioka, T. and Atluri, S. N., "A Method for Determining Dynamic Stress Intensity Factors from COD Measurement at the Notch Mouth in Dynamic Tear Testing," Eng. Fract. Mech., Vol. 16, 1982, pp. 333-339.

[17] Popelar, C. H., Anderson, Jr., C. E., and Nagy, A., “An Experimental Method for Determining Dynamic Fracture Toughness," Exp. Mech., Vol. 40, 2000, pp. 401-407.

[18] Tada, H., Paris, P., and Irwin, G., The Stress Analysis of Cracks Handbook, Paris Productions, Inc., St. Louis, Missouri, 1985. 